\title{
Psicologia Educacional no Ensino Superior: a partir de práticas desenvolvidas em um programa de apoio ao estudante
}

\author{
Educational Psychology in Higher Education: from practices developed in a student support
} program

Psicología de la educación en la educación superior: a partir de prácticas desarrolladas en un programa de apoyo al estudiante

\section{Resumo}

Este artigo tem o objetivo de relatar sobre a importância da prática da psicologia educacional no ensino superior. Compreende-se como um relato de experiência de cinco estagiárias, em um programa de apoio ao estudante universitário, a partir dos registros em relatórios e transcrições das estagiárias do curso de Psicologia e o diário de campo da orientadora provindo de suas supervisões. O cenário deu-se em uma universidade particular do nordeste brasileiro, durante o período de fevereiro de 2020 a junho de 2021, baseado nas atividades desenvolvidas, em parte presencial e em parte virtual, devido a pandemia que assola o mundo. Adotou-se a análise de conteúdo e elencou-se as categorias: apoio à acessibilidade e inclusão, apoio psicopedagógico, escuta psicológica, facilitação de oficina de habilidades emocionais, o impacto do atendimento online e os ganhos na formação do psicólogo. Foi contatado que as múltiplas atividades desenvolvidas no estágio, promoveu ganhos na formação das estagiárias e desenvolveu nova forma de perceber e acolher as diferenças no contexto educacional e social.

Palavras-chave: Psicologia escolar; Psicologia educacional; Formação do psicólogo; Ensino superior.

\begin{abstract}
This article aims to report on the importance of the educational psychology practice in higher education. It is understood as an experience report of five interns, in a university student support program, based on records in reports and transcripts of the Psychology course interns and the field diary of the advisor by her supervision. The setting took place at a private university from northeastern Brazil, during the period from February 2020 to June 2021, from the activities developed, partly in presential and partly online, due to pandemic that devastates the world. Content analysis was applied and listed the categories: accessibility and inclusion support, psych pedagogical support, psychological listening facilitation of emotional skills workshop, the online support's impact and the gains in psychologist's formation. It was found that the multiple activities developed in the internship promoted gains in the training of interns and developed a new way of perceiving and accepting differences in the educational and social context.
\end{abstract}


Keywords: School psychology; Educational psychology; Psychologist's formation; Higher education.

\section{Resumen}

Este artículo tiene como objetivo informar sobre la importancia de la práctica de la psicología educativa en la educación superior. Se entiende como un informe de experiencia de cinco pasantes, en un programa de apoyo a estudiantes universitarios, con base en los registros en informes y transcripciones de los pasantes del curso de Psicología y el diario de campo del supervisor de los alumnos. El escenario tuvo lugar en una universidad privada en el noreste de Brasil, de febrero de 2020 a junio de 2021, a partir de las actividades desarrolladas, en parte presencial y en parte en línea, debido a la pandemia que asola al mundo. Se adoptó el análisis de contenido y se enumeraron las siguientes categorías: apoyo a la accesibilidad e inclusión, apoyo psicopedagógico, escucha psicológica, taller de facilitación de habilidades emocionales, impacto de la atención en línea y ganancias en la formación de psicólogos. Se constató que las múltiples actividades desarrolladas en la pasantía promovieron ganancias en la formación de los pasantes y desarrollaron una nueva forma de percibir y aceptar las diferencias en el contexto educativo y social.

Palabras clave: Psicología escolar; Psicología educacional; Formación de psicólogos; Enseñanza superior.

\section{Introdução}

O contexto universitário é parte de um novo mundo para os jovens que ingressam no Ensino Superior. O estudante sai de um espaço protetivo da escola, onde era lembrado por sinetas, professores e coordenadores sobre a hora de intervalo, a hora da entrada e da saída, dia e horário da entrega de tarefas e até de como deve ser feita a atividade, para um mundo que lhe exige autonomia e autorresponsabilidade. E que, tantas vezes, gera medo, ansiedade, baixo rendimento e evasão. O que pode ser agravado se a instituição não respeitar e acolher as diferenças. Daí a proposta de ampliação do programa de acolhimento ao aluno com deficiência para ser, também, um de espaço de prática da Psicologia Educacional no ensino superior, a ser desenvolvida por psicólogos em formação, por meio de um estágio supervisionado, considerando que,

A formação globalizante do psicólogo exige em sua formação uma ampliação de leitura de mundo e desenvolvimento do respeito à diversidade humana, que cresce à medida que as pessoas passam a conquistar os seus espaços mais diversos e buscam os seus direitos como cidadãos (Joca, Munguba, Barbosa \& Sato, 2019, p. 19).

Então, com a participação dos psicólogos em formação, o programa prestava-se a acolher estudantes dos diversos cursos de uma Instituição de Ensino Superior (IES) da rede privada de ensino, em suas diferenças, de forma inovadora, pois, Santos, Souto, Silveira, Perrone e Dias (2015), em seus estudos sobre a Psicologia Escolar e Educacional, assinalam que há poucos registros sobre as ações de assistência estudantil no âmbito do ensino superior privado. Em contrapartida, há um grande aumento de demanda do sofrimento psíquico dos estudantes universitários, como Carlesso (2019) aponta para necessidade de atenção à saúde mental desses estudantes, a partir de ações preventivas e de acolhimento nas universidades.

Como dito, inicialmente, o programa foi criado com o foco nas pessoas com deficiência, entretanto, após três anos houve a mudança de gestão que percebeu a necessidade de ampliação nos atendimentos, face a constatação desse sofrimento revelado pelos estudantes. Então,

foi dada maior atenção às demandas de aprendizagem e desatenção, como também, foi acrescentado o apoio psicológico ao aluno com questões emocionais que interferiam em seu processo acadêmico. Vale salientar que não se tratava de psicoterapia, mas de uma escuta psicológica àquele que traz a sua dor para o mundo acadêmico. Com isso, houve a possibilidade de abertura de estágio em Psicologia Educacional (depois nominada, pela instituição, de Processos Educativos e Sociais) (Munguba \& Joca, 2020, p.16).

O programa traz a importância de acolher as demandas sociais dos indivíduos e grupos e, principalmente, respeitar a diversidade que compõem os espaços de intervenção social e educativa de acordo com a ética profissional. Para o psicólogo em formação, nesse programa, faz-se imprescindível apropriar-se do assunto referente a acessibilidade e inclusão, bem como ter o cuidado de lidar com as diferenças, de maneira que compreenda as pessoas em suas particularidades, sendo importante acolher e respeitá-los como sujeitos e não como diagnóstico ou problema. Por considerar que, 
A compreensão da subjetividade de alunos com necessidades especiais vem desafiar o estudo do processo de inclusão escolar, pois como se sabe são sujeitos que há muito são reféns de atribuições e configurações sociais que os desconsideram como sujeitos ativos e construtores (Gonzalez, 2008, p.55).

Acresce que o diagnóstico não deve limitar alguém, é claro que há determinados limites, porém um diagnóstico não define um sujeito ao todo. A precipitação em estabelecer o diagnóstico, sob o risco de rotular o paciente em uma patologia, pode empobrecer, em muito, a escuta, ao torná-la hipersensível a certas falas do sujeito e/ou surda a outras (Coutinho, 2007). Assim, pode-se dizer que o diagnóstico pode ser tomado como um mal necessário ou como um bem perigoso, para que não seja limitante para o sujeito nem reduza as possibilidades do aluno. Por isso a instituição necessita dos laudos para o processo de inclusão e as estratégias de acompanhamento, mas não para a escuta do sujeito.

O estágio possibilita uma prática psicológica em processos e contextos educativos e sociais, diante disso, a preparação do psicólogo em formação, neste cenário, inicia-se a partir de revisão de literatura com a temática de psicologia educacional no ensino superior, pessoas com deficiência, inclusão e acessibilidade no ensino superior, formação do psicólogo e sofrimento psíquico no ensino superior; vivências com a técnica de paciente ator; estudo de caso e, posteriormente, as trocas durante as supervisões a partir das atividades desenvolvidas durante o estágio. Para dessa forma iniciarem as práticas psicológicas no contexto acadêmico, que visem a facilitação das condições que atuam sobre os processos que perpassam o sujeito, auxiliá-los em suas questões pedagógicas e emocionais, realizando apoio e escuta sensível com o intuito de contribuir para a diminuição do sofrimento psíquico no ensino superior.

Vale destacar que o período desse estágio, foi surpreendido com a necessidade de interromper as atividades presenciais, pois, atualmente, o mundo vive um momento atípico de pandemia pelo novo coronavírus, responsável por causar a doença SARS-COV-2, então as atividades a serem realizadas in locum, presencialmente, foram alcançadas através do ambiente virtual (online), na forma de atendimentos efetuados por intermédio da plataforma Google Meet. O fato exigiu a preparação de todos os envolvidos para não baixar a qualidade dos serviços ofertados pelo setor. Em outras palavras, o programa manteve seu compromisso em todas as atividades prestadas, as quais foram adaptadas por via tecnológica de forma que repensasse e ampliasse o nosso olhar e as nossas práxis. Além de buscar informações e orientações, por meio de lives e informativos do Conselho Federal de Psicologia e do Conselho Regional de Psicologia (CRP-11).

\section{Metodologia}

Este estudo configura-se como pesquisa qualitativa e constitui-se como um relato de experiência (Minayo, Deslandes, \& Gomes, 2015), a partir do que foi vivido no estágio em Psicologia Educacional, que na instituição é nominado como Processos Educativos e Sociais, tomando como apoio a pesquisa documental (Minayo, Deslandes, \& Gomes, 2015), a partir dos relatórios finais do estágio, as transcrições de atendimento das cinco estagiárias e os registros da orientadora de estágio (coordenadora do programa de apoio ao estudante). "É preciso ressaltar que um relato coletivo não significa um conto homogneo e, sim, uma história em que os diversos interesses e as várias visões tenham lugar e possibilidade de expressão" (Minayo, 2012, p. 624).

Traz como objetivo relatar sobre a importância da prática da psicologia educacional no ensino superior, a partir das atividades desenvolvidas pelas estagiárias, que compreendem: o atendimento individual a partir de uma escuta psicológica sensível, atendimento com foco psicopedagógico, apoio à promoção da acessibilidade e inclusão de pessoas com deficiência e necessidades educacionais específicas, facilitação de grupo em oficina de habilidades emocionais, no período de fevereiro de 2020 a junho de 2021. O estágio exigia cinco horas semanais, entretanto, duas das estagiárias eram bolsistas institucionais, as quais contavam com mais 10 horas semanais, por isso assumiram a coordenação dos registros, por meio de formulários e transcrições e os agendamentos de suas respectivas turmas. Para análise dos dados, considerou-se o diário de campo da 
orientadora e os relatórios das estagiárias e transcrições de atendimento dos estudantes nos atendimentos individuais e em grupo. Acrescenta-se que as atividades do programa abrangem todos os cursos da universidade, nas diversas áreas: a partir dos centros de comunicação e gestão, exatas, jurídica e saúde.

Por fim, as informações coletadas foram consideradas e se fez uso da análise de conteúdo proposta por Bardin (2016). Da análise foram elencadas as categorias: apoio à acessibilidade e inclusão, apoio psicopedagógico, escuta psicológica, facilitação de oficina de habilidades emocionais, o impacto do atendimento online e os ganhos na formação do psicólogo.

\section{Resultados e Discussão}

A partir das experiências relatadas pelas cinco psicólogas em formação, em seus estágios de Processos Educativos e Sociais (Psicologia Educacional), com atuações diante das demandas de um setor de acolhimento ao estudante, iremos expor os resultados e desenvolver um diálogo com os autores.

As demandas, deste programa que abriga o serviço de Psicologia Educacional, na instituição, são muito diversas, desde as dificuldades de aprendizagem, a deficiência física, deficiência visual, deficiência auditiva, síndromes, transtornos e as questões de saúde mental. E requisitam o embasamento teórico das psicólogas em formação a fim de realizar a junção de teoria e prática durante o estágio. Desse modo, obtiveram experiência e, de acordo com os documentos analisados, registraram, durante o período deste estudo, 110 atendimentos psicopedagógicos, 295 escutas psicológicas e 8 encontros de grupo, na oficina de habilidades emocionais com o foco nas dificuldades diante do Trabalho de Conclusão de Curso (TCC), além de contribuir com a adaptação de material para alunos surdos e cegos, a fim de garantir a participação com equidade em suas disciplinas.

O estágio foi realizado em tempo de pandemia e com isso houve estudos preparatórios sobre confinamento, atendimento em crise, e o papel do psicólogo em situações críticas e desastres. Além do setor ter realizado uma busca ativa àqueles que apresentavam vulnerabilidade: pessoas com deficiência, estudantes com baixo rendimento, comprometimento da saúde mental e estudantes de outros países. Considerando que

Vivenciar um contexto de pandemia não se configura a partir de emoções positivas e prazerosas, pelo contrário, proporciona a presença de emoções negativas que são bastante desconfortáveis de serem vividas no âmbito do sujeito (como por exemplo medo, ansiedade, entre outras), contudo, também são potentes para promover reflexões e construções de novas perspectivas (Pott, 2020, p. 49712).

Foi percebido que o estágio vivido em suas diversas nuances, contribuiu com a formação do psicólogo, para além da área educacional. Pois, como assinalam Carvalho, Silva, Joca e Munguba (2019, p. 16-17) "a preparação, mediante um ensino de qualidade, necessita do estabelecimento da práxis para construir o exercício de uma prática assertiva com competência no uso dos saberes de sua área, por intermédio de práticas éticas e respeitosas diante das diferenças humanas".

A seguir faremos a discussão dos resultados, a partir das seis categorias elencadas: apoio à acessibilidade e inclusão, apoio psicopedagógico, escuta psicológica, facilitação de oficina de habilidades emocionais, o impacto do atendimento online e os ganhos na formação do psicólogo.

\subsection{Apoio à acessibilidade e inclusão}

A inclusão não é somente para os que apresentam alguma deficiência física, visual, auditiva ou intelectual, ela é compreendida de forma mais ampla e insere o estudante que tem alguma dificuldade, seja de aprendizado, emocional, síndromes, sequelas neurológicas etc. E o apoio no processo de inclusão e acessibilidade deu a oportunidade às estagiárias de enveredarem e conhecerem de perto as pessoas com deficiência e ampliarem as suas possíveis práticas futuras. Pois, 
acreditamos que, "as demandas de políticas públicas que promovam a adequada participação social, assim como a minimização de barreiras, inclusive as atitudinais, apontam para a necessidade urgente de que todos se envolvam na discussão dessa abordagem social da deficiência (Serra. Joca, Oliveira, \& Munguba, 2020, p.9).

Assim, compreenderam que sem o apoio necessário não haveria como as pessoas com deficiência participarem de modo equânime do mundo universitário. Como assegura, Sá (2018, p. 11)

(...) as riquezas da diversidade são usufruto social: em uma sociedade complexa do século XXI, os princípios da equidade devem tornar-se parte integrante da educação em geral, pois este é o predicado de uma sociedade de cidadãos, uma sociedade que não considera diferentes menos capazes.

Diante da tomada de consciência sobre a condição da pessoa com deficiência e as suas potencialidades, "é preciso elucidar que as trilhas percorridas na busca de desvencilhar-se do rótulo de deficiência, até chegar a uma perspectiva de diferença representa um longo caminho" (Joca, Munguba, Carvalho Neto, Carvalho, \& Silveira, 2016, p. 9).

Esse contato com as diferenças, por meio da aceitação e acolhimento, respeitando as limitações, deu a oportunidade de entrar em contato com os professores e familiares para orientar sobre estratégias de ensino e avaliação que permitissem a acessibilidade e, até, proporcionou o contato, pela primeira vez, no que diz respeito a ação do psicólogo com autista adulto, aproximando esse fazer no âmbito dos processos educativos e sociais. Como assinalam Carvalho Neto, Silveira e Joca (2018, p. 117) "foi mediante este programa que foi possível presenciar e observar na prática a vida dos sujeitos que possuem alguma necessidade especial dentro de uma instituição de ensino superior".

Desse modo percebeu-se que é um ganho de mão dupla, pois se criamos condições de acessibilidade para as pessoas com deficiência, isso promove a sua permanência na universidade e possibilita os seus sonhos de obter a graduação. À medida que, também, a experiência dos psicólogos em formação, com a proposta de inclusão, proporciona novas lentes no modo de entender o mundo, porque trabalhar com inclusão leva a uma constante motivação, por se entender que o trabalho é sempre "inacabado" e sempre faltará algo para se pensar, melhorar ou até mesmo descobrir.

\subsection{Apoio psicopedagógico}

O apoio psicopedagógico é ofertado aos estudantes com ou sem deficiência e, como as demais atividades, é realizado pelas psicólogas em formação sob a orientação da coordenadora do programa e supervisora de estágio, a partir da demanda de dificuldade de aprendizagem, seja em uma ou em todas as disciplinas do semestre, dos transtornos de aprendizagem (dislexia, discalculia, disortografia, disgrafia), do transtorno do déficit de atenção, deficiência intelectual etc. "Essa modalidade de acompanhamento é flexível e depende da coparticipação do estudante em sua forma de aprender e a estudar com autonomia e comprometimento" (Oliveira, Joca, \& Munguba, 2019, p. 111). Compreende a orientação de leitura, orientação de estudo e a organização de planner de atividades com a participação direta do aluno, além da orientação aos professores.

"O estudante que revela questões de aprendizagem necessita ser compreendido na totalidade do sujeito que aprende, não o percebendo somente diante de suas dificuldades ou fracasso escolar" (Oliveira et al, 2019, p.111). Assim, aquele que necessita desse apoio deve ser atendido em um ambiente favorável e de credibilidade no potencial do aluno, que o convoque a refletir sobre si mesmo, seus desejos pessoais e acadêmicos, como também, levá-lo a desenvolver comprometimento e tornarse coparticipe do processo de ensino-aprendizagem, a fim de que perceba o sentido de estar em uma universidade, identificar quais os seus objetivos e o que se faz necessário para alcançá-los. Mas, vale salientar que o planejamento e as intervenções são individualizados e "o modo como o facilitador de aprendizagem atua depende do aluno e de sua necessidade específica. Por isso desde o primeiro contato, é necessário perceber qual a real demanda do estudante, as possíveis formas de intervenção para elaborar um plano de atendimento" (Oliveira et al, 2019, p.111). 
Complementa-se, ainda, que essa inclusão pode ser mais árdua que a inclusão de pessoas com deficiência física ou sensorial, pois, depende muito de um novo olhar de todos os envolvidos na instituição e na disposição para inovar na didática do professor e na aceitação dos pares.

\subsection{Escuta psicológica}

Percebeu-se claramente no programa que a maior demanda se manifesta a partir de necessidades de apoio psicológico de várias ordens, sendo que o mais comum são os transtornos de ansiedade que, de certa forma, retratam a sociedade atual onde o sujeito é convocado a se dispor ao cumprimento de várias exigências internas e principalmente externas que levam a exaustão e ao adoecimento psíquico, o qual traz em seu bojo várias problemáticas relacionais e circunstanciais. O que também fundamenta e agrega o grande valor da existência de um serviço indispensável, no ensino superior, como os que são ofertados pelo programa. Pois, muitas vezes, traziam a queixa de baixo rendimento, mas se revelava um desconforto emocional. Isso porque "o sofrimento psíquico pode ser causa ou efeito do baixo rendimento acadêmico. Assim, a escuta psicológica tem sido determinante para esclarecer 'o que vem primeiro' nesse processo, o que possibilita a estruturação de estratégias adequadas para cada estudante" (Joca et al, 2019, p. 35).

Essa escuta psicológica, em muitos casos, serviu como triagem para encaminhamento à clínica escola da universidade, para psicoterapia, com o preenchimento de documentação previamente acordada entre as coordenações do programa e da clínica.

\subsection{Facilitação de oficina de habilidades emocionais}

Durante os atendimentos com os estudantes, foi percebido que traziam experiências negativas da escola que interferiam em sua autoestima, nas relações e no medo de atividades avaliativas. Isso porque

No que se refere ao ambiente da sala de aula, o corpo docente, geralmente, é orientado a manter o domínio sobre seus alunos, visto que os discentes são dirigidos a um estado progressivo de medo, onde os alunos mostram-se receosos à possibilidade de se depararem com a ridicularização pública, críticas e fracasso social (Oliveira, Silva, Joca, \& Munguba, 2018, p. 45).

A partir da reflexão sobre essa demanda, foi criada a oficina de habilidades emocionais (Pre)tensão, em 2016, para trabalhar, em grupo, o medo de prova e apresentação de trabalhos. Tem sido dado o seguimento, ano a ano, com a modalidade de grupo aberto e com a facilitação de psicólogas em formação. A oficina "visa oferecer suporte emocional aos alunos dos cursos de graduação que apresentam ansiedade de tal modo que acabam paralisando diante das situações avaliativas, o que resulta em uma interferência em seu desempenho acadêmico" (Silva, Carvalho, Joca, \& Munguba, 2018, p.176).

No ano de 2020 não foi possível dar continuidade ao grupo, por conta da adaptação de vários recursos a serem desenvolvidos para o trabalho remoto, então nos debruçamos no planejamento para retomarmos no ano seguinte a partir das demandas identificadas nas buscas por atendimento. Percebemos que o TCC estava sendo a grande preocupação dos estudantes, então foi dado um foco maior a elaboração e apresentação de trabalho. Onde realizamos 8 encontros (online) com troca de experiências e sentimento diante dessa tarefa para a conclusão do curso.

O grupo durou todo semestre letivo e culminou com a troca dos projetos e das pesquisas realizadas para composição do trabalho de conclusão do curso, revelando uma troca rica e com respeito a cada componente, pois como assinalam Afonso et al. (2009), "grupo funciona como um campo de referências cognitivas e afetivas, onde o sujeito se integra e se reconhece, podendo tanto bloquear quanto estimular processos criativos e críticos". Assim, por meio do compartilhamento e acolhimentos todos se sentiram de alguma forma pertencentes e apoiados, conseguindo destravar o medo de apresentação de trabalhos. 


\section{5 $\mathrm{O}$ impacto do atendimento online}

A população mundial foi surpreendida com o advento da pandemia. E sendo a SARS-COV-2 uma doença transmitida de forma muito rápida por pessoas que estão em contato próximo, através do toque, tosses e espirros, a forma mais eficaz que as organizações de saúde recomendaram, para amenizar a situação, foi o distanciamento social. Por outro lado, "a saúde mental da população durante uma pandemia de grande magnitude como esta implica em uma perturbação psicossocial que pode ultrapassar a capacidade de enfrentamento da população afetada" (Oliveira, 2021, p.13)

Acresce que, como já explicitado,

Os níveis de sofrimento mental encontrados em estudantes universitários têm sido bastante significativos, denotando a urgência em desenvolver cuidados em saúde mental e estratégias de políticas públicas para esta população, principalmente no enfrentamento da atual pandemia (Carvalho \& Sousa, 2021, p. 6).

Daí o programa procurou se organizar e passar as orientações, para as psicólogas em formação, sobre como poderiam ser realizados os atendimentos online, de acordo com as diretrizes estabelecidas pelo Conselho Federal de Psicologia e o Conselho Regional de Psicologia. Buscou leituras sobre situações de crise, confinamento e teleatendimento, além do uso da metodologia de paciente simulado (paciente ator) como forma de preparação da equipe, para essa nova modalidade. Durante a preparação para nova forma de atendimento, foi percebido que,

Para que haja saúde mental em um contexto de pandemia, muitas vezes é necessário a migração das emoções, a ressignificação das mesmas, de modo que as afecções que causam padecimento, imobilidade, sejam transformadas possibilitando a expressão da potencialidade humana (Pott, 2020, p. 49716).

Com isso, ao longo do estágio percebeu-se um aprimoramento da escuta psicológica, em face das demandas desafiadoras que se evidenciaram ao longo do semestre, em razão da pandemia SARS-COV-2 e nesse contexto, "torna-se necessário uma serie de organizações e restruturações que envolvem desde o âmbito das políticas educacionais até o processo de ensino dos professores e modos de aprendizagem de alunos" (Pott, 2020, p. 49709)

Em consonância ao que foi dito, o uso da interface virtual para atendimentos online foi uma inovação que trouxe diferente dinâmica frente aos desafios do momento presente, legando também outro nível de experiência para o contexto profissional do psicólogo em formação diante dos estudantes que se mostravam com ansiedade, enlutados, perdidos diante das aulas online e com quadros depressivos graves.

\subsection{Ganhos na formação do psicólogo}

A oportunidade de realizar o estágio em um programa de acolhimento ao aluno no ensino superior, perpassada pelo respeito as diferenças, acresce de forma significativa na formação do estudante de psicologia, para além dos conhecimentos adquiridos no decorrer do processo acadêmico, porque trabalhar com inclusão no ensino superior gera uma constante aprendizagem diante dos desafios e ensinamentos vividos na prática. Além de possibilitar um olhar subjetivo para o sujeito, no que diz respeito a ação do psicólogo na práxis e aproximar esse fazer no âmbito dos processos educativos e sociais com a proposta efetiva de contribuir com a instituição.

É relevante acrescentar que o processo metodológico da disciplina de Estágio foi composto por estudos e discussões em grupo na área da inclusão e da acessibilidade, também, por estudos de caso, elaboração de texto-sentidos, que proporcionaram análises e discussões muito precisas para a prática das psicólogas em formação. Somaram-se a isto, os encontros teórico-práticos de formação continuada, que trouxeram discussões riquíssimas no âmbito dos processos socioeducativos. Bem como a partilha de experiências com os colegas em supervisão engradeceram sobremaneira a experiência de estágio. Diante disso, pode-se afirmar que "a experiência em um programa de apoio que respeita os direitos 
humanos e as diferenças, leva o psicólogo em formação a considerar a si e o outro a partir de uma responsabilidade social e do direito ao exercício da cidadania" (Carvalho Neto, Silveira, Joca, \& Munguba, 2016, p. 2).

Compreende-se, assim, que o fazer do psicólogo também é ressaltado com importância no manejo da relação alunoinstituição ao nos prepararmos para pensar, prevenir ou orientar sobre as possíveis formas de inclusão no ensino superior, por nos convocar para termos olhares atentos às diferenças e a dor dos sujeitos e, desse modo, tornar possível que a universidade seja um lugar de todos.

\section{Considerações Finais}

A importância do tema da inclusão e a possibilidade de ampliar o olhar para essa temática, não somente a partir de teorias e leis que fundamentam a educação inclusiva, mas, também, poder observar e experienciar diretamente a partir dos que demandam essa necessidade de serviço, numa possibilidade de realmente conviver com as diferenças e ver a importância desse tema colocado em prática, acompanhar de perto e fazer parte como agente construtor e auxiliar dessa realidade, faz um grande diferencial na formação do estudante de psicologia. Em outras palavras, a experiência que dispõe o PAP, tem sido referência para o apoio e suporte de alunos na rede de ensino superior, visando agregar experiência e conhecimento para os alunos de psicologia verem na prática a relevância de conteúdos estudados ao longo do curso, podendo oportunizar a realização da junção da prática com a teoria.

Constatou-se que a experiência do psicólogo em formação no Ensino Superior, foi possibilitada a partir da oportunidade da vivência do fazer psi por meio da relação desenvolvida com a equipe técnica, a orientadora e a troca com os pares, com respeito e ética nos atendimentos e no desenvolvimento de projetos. Por fim, o escopo maior dos processos socioeducativos, qual seja, elucidar o papel ocupado pelo psicólogo em múltiplos contextos educativos e sociais, bem como diagnosticar demandas nesta base, onde o profissional pode e deve atuar de modo crítico e articulador, reverberou de forma positiva amplamente na formação.

Diante da falta de literatura com a temática da formação do psicólogo, perpassada pela educação inclusiva e a estruturação de programas de acolhimento das demandas diversas dos universitários, sugere-se a necessidade de novas pesquisas sobre o tema, por de grande relevância social e revela a premência de reflexão diante do contexto contemporâneo.

\section{Referências}

Afonso, M. L. M., Vieira-Silva, M., \& Abade, F. L. (2009). O processo grupal e a educação de jovens e adultos. Psicologia em Estudo. 14(4), p. 707-715.

Carlesso, J. P. P. (2019). Os desafios da vida acadêmica e o sofrimento psíquico dos estudantes universitários. Research, Society and Development, 9(2), e82922092. http://dx.doi.org/10.33448/rsd-v9i2.2092

Carvalho, A. F. M. de, \& Sousa, G. G. de (2021). Os efeitos psicológicos do distanciamento social causado pelo novo Coronavírus em estudantes universitários. Research, Society and Development, 10(8), e9710817245. http://dx.doi.org/10.33448/rsd-v10i8.17245

Carvalho, D. R., Silva, R. N., Joca, T. T., \& Munguba, M. C. (2019). A formação do psicólogo educacional e seus novos contextos: um relato de experiência. Educação em Debate. 41(78), 9-19. http://www.periodicosfaced.ufc.br/index.php/educacaoemdebate/article/view/824/457

Carvalho Neto, A. S., Silveira, F. C. dos S., Joca, T. T., \& Munguba, M. C. (2016). O direito à educação e a inclusão no ensino superior: prática de um programa de apoio aos estudantes para formação dos indivíduos. Anais do II Congresso Internacional de Educação Inclusiva e Jornada Chilena Brasileira de Educação Inclusiva, Campina Grande, PB, Brasil, 2. http://editorarealize.com.br/revistas/cintedi/trabalhos/TRABALHO_EV060_MD 1_SA12_ID3648_23102016203438.pdf

Coutinho, A. H. S. de A. (2007). Escutar é preciso, diagnosticar não é preciso. Reverso, 29(54), 99-108. http://pepsic.bvsalud.org/scielo.php?script= sci_arttext\&pid=S0102-73952007000100015

González Rey, F. L. (2011). Os aspectos subjetivos no desenvolvimento de crianças com necessidades especiais: além dos limites concretos do defeito. In A. M. Martizez \& M. C. V. R. Tacca, (Orgs.), Possibilidades de aprendizagem: ações pedagógicas para alunos com dificuldade e deficiência (pp. 47-70). Alínea.

Joca, T. T., Munguba, M. C., Barbosa, J. W., \& Sato, R. H. N. P. (2019). Espaço de atenção ao aluno: formação do psicólogo perpassada pela educação inclusiva e o sofrimento psíquico no Ensino Superior In F. H. de F. Miranda (Org.), Psicologia e interdisciplinaridade: encontro de saberes (19-38). Paco Editorial. 
Research, Society and Development, v. 10, n. 10, e460101019126, 2021

(CC BY 4.0) | ISSN 2525-3409 | DOI: http://dx.doi.org/10.33448/rsd-v10i10.19126

Joca, T. T., Munguba, M. C., Carvalho Neto, A. S., Carvalho, D. R., \& Silveira, F. C. dos S. (2016). Da deficiência à diferença: um estudo da percepção do ser surdo. Anais do VII Congresso Brasileiro de Educação Especial, São Carlos, SP, Brasil. https://proceedings.science/cbee7/papers

Minayo, M. C. S. (2012). Análise qualitativa: teoria, passos e fidedignidade. Ciência e Saúde Coletiva. 17(3), 621-626. https://www.scielo.br/j/csc/a/39YW8 sMQhNzG5NmpGBtNMFf/?lang=pt\&format=pdf

Minayo, M. C. de S., Deslandes, S. F., \& Gomes, R. C. (2015). Pesquisa social: teoria, método e criatividade. (34a ed.). Vozes.

Munguba, M. C., \& Joca, T. T. (2020). Prática baseada em evidências como ferramenta da educação inclusiva. In T. T. Joca, \& M. C. Munguba (Orgs.), Educação Inclusiva: perspectivas complementares no respeito às diferenças. (7-27). Paco Editorial.

Oliveira, A. R. M. N., Joca, T. T., \& Munguba, M. C. (2019). Atendimento psicopedagógico e a promoção da saúde e bem-estar no ensino superior - um relato sobre deficiência intelectual. In: A. Gomes, C. Nunes, E. Costa, E. Pacheco, J. Santos, J. Rosa, M. Fernandes, P. Martins, R. Matavelli, R. Chiodeli, \& Saul de Jesus. (Orgs.). Book of Proceedings - V Congresso Ibero-Americano e Luso-Brasileiro de Psicologia da Saúde I Congresso Promoção da Saúde e do BemEstar no Ensino Superior. CIEO, 109-113. https://cieo15.wixsite.com/psaude2019/copy-of-galeria-fotos

Oliveira, A. R. M., Silva, R. N., Joca, T. T. \& Munguba, M. C. (2018) Oficina de Habilidades Emocionais como estratégia de prevenção do fracasso escolar no ensino superior, um relato de experiência. In A. Kaplan \& E. Ostrovsky (Colab). Actas Digitales del IV Congreso Internacional sobre problemáticas en educación y salud. (pp. 44-51). Sociedades Complejas.

Oliveira, E. N. (2020). Saúde Mental durante a Pandemia do novo Coronavírus: algumas reflexões necessárias. Research, Society and Development, 9(8), e413985478. http://dx.doi.org/10.33448/rsd-v9i8.5478

Pott, E. T. B. (2020) Contribuições da Psicologia Escolar para o ensino superior em um contexto de pandemia: o papel da construção de coletivos. Brazilian Journal of Develop. 6(7), 49707-49719. 10.34117/bjdv6n7-571

Sá, H. L do C. (2018). Em direção a um processo mais inclusivo na educação superior, para além da retórica. In T. T. Joca, M. C. Munguba, D. R. Carvalho, N. dos S. Almeida, \& E. C. F. e Silva (Orgs.), Nuances da inclusão no ensino superior (9-12). Paco Editorial.

Santos, A. S., Souto, D. da C., Silveira, K. S. da S., Perrone, C. M., \& Dias, A. C. G. (2015) Atuação do Psicólogo Escolar e Educacional no ensino superior: reflexões sobre práticas. Revista Psicologia Escolar e Educacional. 19(3), 515-524.

Serra, I. O., Joca, T. T., Oliveira, A. R. M. N., \& Munguba, M. C. (2020). A pessoa com deficiência e os entrelaces com as questões de gênero e de sexualidade. Research, Society and Development, 9(8), e728986157. http://dx.doi.org/10.33448/rsd-v9i8.6157

Silva, R. N., Carvalho, D. R., Joca, T. T., \& Munguba, M. C. (2018). Do medo de avaliação à quebra das barreiras internas intermediada pelos encontros da oficina (Pre)tensão. In T. T. Joca, M. C. Munguba, D. R. Carvalho, N. dos S. Almeida, \& E. C. F. e Silva (Orgs.), Nuances da inclusão no ensino superior (173-182). Paco Editorial. 